\title{
To Study the Attitude of Staff in a Tertiary-care Trauma Center toward Patient's Relatives
}

\author{
Ravinder Ahlawat ${ }^{1}$, Amit Lathwal ${ }^{2}$, Sanjay Arya ${ }^{3}$
}

\begin{abstract}
Background: In the developed countries, there is a building consensus for more open visiting polices and changing the role of family as the active care provider. Kangaroo mother care is one such accepted norm, which has transformed the organization of obstetrics and pediatrics ward. It is the right time to check for the readiness of our hospital staff for involving relatives as a co-care provider in our settings. In this part of globe, the presence of patient's relatives $24 \times 7$ in a public hospital is an accepted norm; however, their role has not been studied by the hospital administration and adequate provision has not been translated in the hospital architecture.

Aims: To assess the knowledge and attitude of employees working at the apex acute care hospital, New Delhi toward patient's relatives.

Setting and design: The study design is a survey research using a self-administered questionnaire to elucidate knowledge and attitude of healthcare workers in the apex trauma center.

Materials and methods: A knowledge-and-attitude survey based on a questionnaire was undertaken during July 2016, among willing employees. The performa was distributed to different wards and areas, and was gathered the next day. The questionnaire was developed with the help of the faculty of hospital administration, and a beta analysis was performed before the final application.

Results: A total of 159 performas were collected, of which 2 were rejected because of being incomplete. An estimated $93.6 \%$ respondents favor the idea of family staying at the bedside of a patient in the wards. Most of respondents were young, have 5-10 years of service, were well qualified, and were well versed with patient-care-giving practices. The factors favoring family stay in wards were ease to handle patients with accompanying family, family role in perceived faster recovery, emotional support to the patient, positive role of family in patient feeding, and role of family in reducing patient safety incidence. However, the role of family members in HAl and concerns for the privacy of the relatives were negatively related to the family stay in wards. The majority were not satisfied with the provisions made for the relatives in the hospital. A very high percentage believe that the design of the hospital needs to be changed for providing more space for relatives. The idea of introducing a foldable bed was accepted by a huge majority.
\end{abstract}

Conclusion: With the accumulation of the knowledge that severe hospital-acquired infection (HAl) incidences are not affected by the presence or absence of the relatives near the patient, the level of anxiety, incidences of cardiac complication, and stress hormones' level in the blood are favorably affected by the presence of relatives; family involvement is not just an administrative issue, and it has found clinical implication also. It is time to give bigger roles to the family for patients staying at the hospital.

Keywords: Family of the patient, Indoor ward, Trauma center.

International Journal of Research Foundation of Hospital and Healthcare Administration (2019): 10.5005/jp-journals-10035-1102

\section{INTRODUCTION}

During 1980-1990s, there was a negative perception among staff nurses toward the role of relatives in hospitals and it was believed that relatives hamper patient care. There were also concerns about privacy and stress level of the patients and confidentiality of the patients.

However, in a Fumagalli et al.'s study on the effect of unrestricted visiting policy (UVP) and restricted visiting policy (RVP) on safety and health outcome of patient in an ICU setting, it was observed that UVP does not increase sepsis complication in patients and was associated with reduced cardiovascular complications. $^{2}$

In another study by Kleinpell on visiting hours in ICU, it was reported that the physician felt that there was no delay or uneasiness while examining patient, family stress was reduced and family trust was increased, and there was no perceived interference with delivery of care. ${ }^{3}$

In another study by Marco in Spain to evaluate the role of the belief and attitude of ICU nurses on the effect of open visiting policy on patient, family and nurses, a positive effect of visits of family was observed on the patient as well as on the family. ${ }^{4}$
${ }^{1}$ Office of the Director General Health Services, Health Department of Haryana, Panchkula, Haryana, India

2,3 Department of Hospital Administration, All India Institute of Medical Sciences, New Delhi, India

Corresponding Author: Amit Lathwal, Department of Hospital Administration, All India Institute of Medical Sciences, New Delhi, India, Phone: +91 9350481550, e-mail: amit.lathwal@yahoo.co.in

How to cite this article: Ahlawat R, Lathwal A, Arya S, et al. To Study the Attitude of Staff in a Tertiary-care Trauma Center toward Patient's Relatives. Int J Res Foundation Hosp Healthc Adm 2019;7(1):1-5.

Source of support: Nil

Conflict of interest: None

The design of the ICU has also undergone changes and the contemporary ideal patient room should incorporate three zones: a patient zone, a family zone, and a care-giver zone. ${ }^{5}$ Involvement of the family in the care of indoor patients has been favored by many studies with varied benefits, like reduction of patient safety incidence ("a patient safety incident is any unintended or unexpected incident that could have or did lead to harm for one 
or more patients receiving care). ${ }^{6,9} \mathrm{~A}$ greater involvement of the family in the form of flexible visiting hours has been stated to be beneficial to the patient, family, and the staff. ${ }^{7}$ The attitude of hospital staff toward participation of family members in patient care had been one of the major factors in family member's involvement. $^{6}$

The Institute for Patient and Family-Centred Care in their Mini Toolkit "Partnering with Patients and Families to Enhance Safety and Quality" has advocated that the family is not a visitor to the hospital rather they are a partner in the delivery of health care. It has further highlighted the role that a family can play to reduce patient safety incidences. The role of the family varies across the globe, as the expectation of a family from a hospital and vice versa is different.

India, with lesser expenditure on the health care by the public sector, has a unique opportunity to associate family members as co-care provider during the patient stay in a ward. However, till date, no study has been published in India about the attitude and perception of the HCW toward involvement of family members in patient care.

On the basis of the attitude of the staff, hospitals can take a decision regarding the involvement of family members as co-care providers and if the hospital decides to involve the family members, then a decision has to be taken to provide facilities to the family members during their stay in the hospital.

\section{A IM}

To study the perception and attitude of healthcare worker $(\mathrm{HCW})$ and factors responsible toward involvement of family members in providing care to an in-patient.

\section{Objectives}

- To study the perception and attitude of healthcare worker (HCW) toward involvement of family members in care of indoor patients.

- To identify the factors responsible for the perception and attitude toward involvement of family members in care of indoor patients.

\section{Duration of the Study}

The study was performed during July and August 2016.

\section{Study Population}

The doctors, staff nurses, paramedical staff, and support staff working at the hospital were included in the study.

\section{Study Areas}

The wards, ICU and operation theatres, and support services were included in the study.

\section{Sampling}

All willing staff members in the identified areas formed part of study. Simple random sampling was used to arrive at the desired sample size.

\section{Tool Used}

A questionnaire was designed in the form of closed-ended multiple responses. The questionnaire was developed and a beta testing of the questionnaire was done on the staff nurses of two wards and the questionnaire was modified thereafter. It was validated by the experts on the subject.

\section{Analysis of the Results}

SPSS and Excel were used for descriptive statistic and interrelationship of the various factors.

\section{Observation and Result}

Of the 175 questionnaires distributed, 159 questionnaires were collected. Of the 159 questionnaires, 2 were not included in the study, as the information provided was grossly insufficient and remaining 157 were analyzed.

\section{Sociodemographic Profile}

The respondents were aged between 21 years and 53 years, with the mean age of 33.10; a majority of them were males. Totally, $64 \%$ respondents were posted in wards, $15 \%$ in support areas, $11 \%$ in the operation theatre, and $10 \%$ ICU.

\section{Duration of the Service}

Majority of the participants (63\%) had an experience of 5-10 years.

\section{Educational Qualifiction of the Participents}

Graduates were $47.77 \%, 40.13 \%$ under graduate diploma, and the rest were matriculates.

\section{Attitute Toward Family Involvement in Patient Care}

An estimated $93.6 \%$ of the respondents favored the stay of family members with the patient, whereas $5.7 \%$ were against their stay and $0.6 \%$ were undetermined. These findings are in contrast to the study done in Belgium, in which authors had observed that nurses were not in favor of open door policy. ${ }^{8}$ This response was also corroborated by asking a negatively worded question on the same aspect, wherein the respondents were asked whether the entry of family members in ward can be banned, and whether they will be able to handle the patient on their own. To this question, $74.52 \% \mathrm{HCWs}$ felt that it will be difficult to manage if relatives are not allowed by the bedside, whereas $12.74 \%$ felt that they would be able to handle the patient on their own and $13 \%$ respondent were silent to this.

\section{Number of Family Members in the Ward}

96.8\% of HCWs opined that one relative should be allowed in the ward, whereas $3.2 \%$ believed 2 relatives should be allowed and none favored more than 2 attendants. ${ }^{8}$

\section{Perceived Factors in Favor of Relatives \\ Ease to Handle In-patients}

In the present study, 134 (85.4\%) of the respondents felt that patients with family members can be handled with ease when compared to the patients who are without family members. It is evident that HCW's responsibility and work is offloaded by the family.

\section{Family Role in Fast Recovery}

Majority of the respondents (i.e., 93.6\%) believed that the presence of family members help in a faster recovery. Contrary to the present study, the hospital staff in Belgium felt that family members are important in patient recovery. ${ }^{8}$ The acceptance of the family members by respondents in the present study could be due to several differences in the two systems (Fig. 1). 


\section{Perceived Benefit from the Family Members}

The majority of the HCWs opined that patients are less apprehensive and feel more secure in the presence of relatives. $\mathrm{HCW}$ felt that the presence of relatives by the bedside helps in overcoming fear (Fig. 2). The results are in sync with other studies

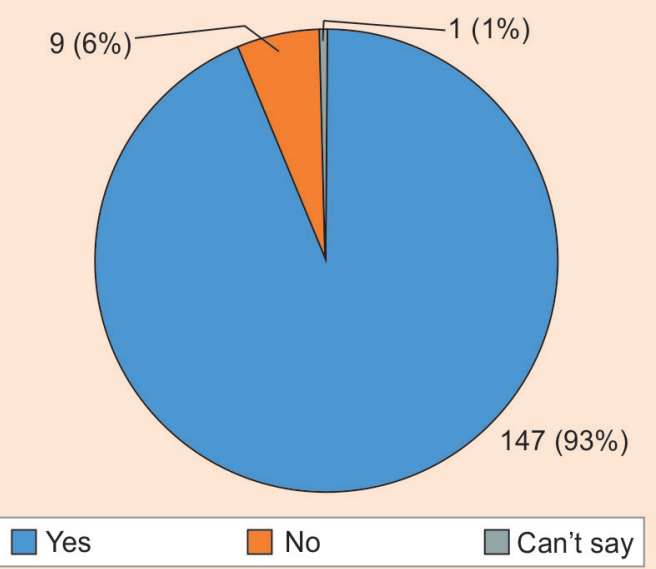

Fig. 1: Attitude toward family involvement in patient care

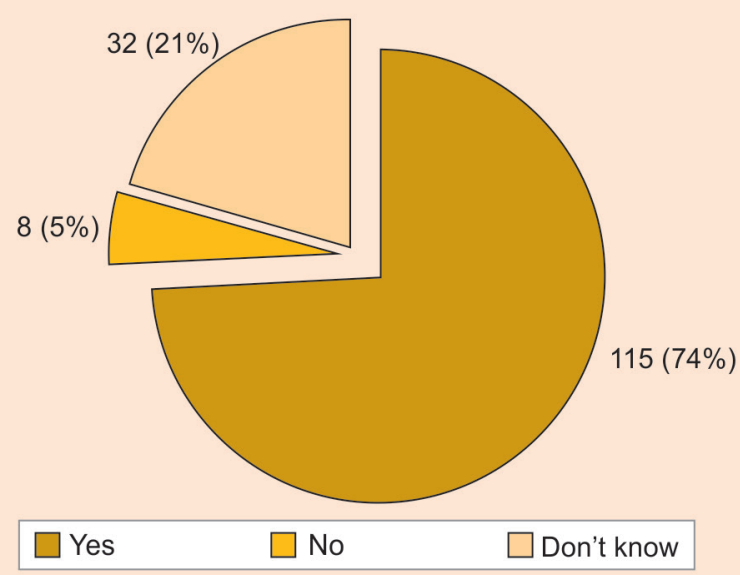

Fig. 3: Are family members helpful in reducing patient safety incidences?

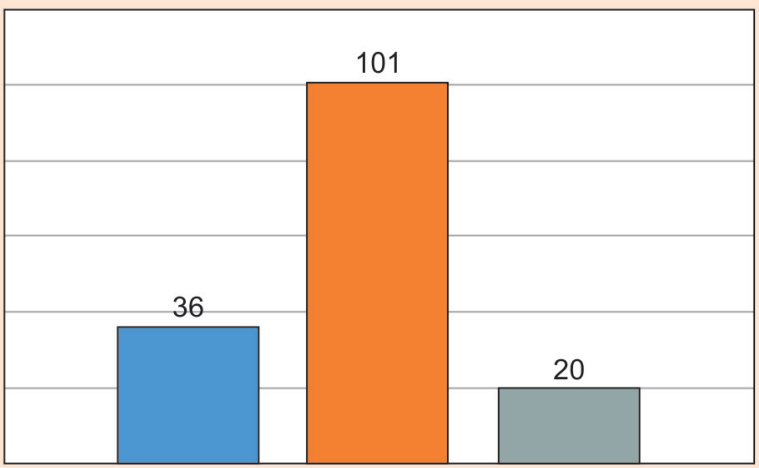

Yes, sufficient

$\square$ No

Can't say

Fig. 5: Are provisions for patient's family members sufficient? by Fumagalli et al., which reported a reduction in anxiety, cardiac complication, fear of the unknown in the presence of relatives. It has also been documented that the level of stress hormones in the blood of patients is affected by the presence or absence of relatives (Figs 3 to 8 ).

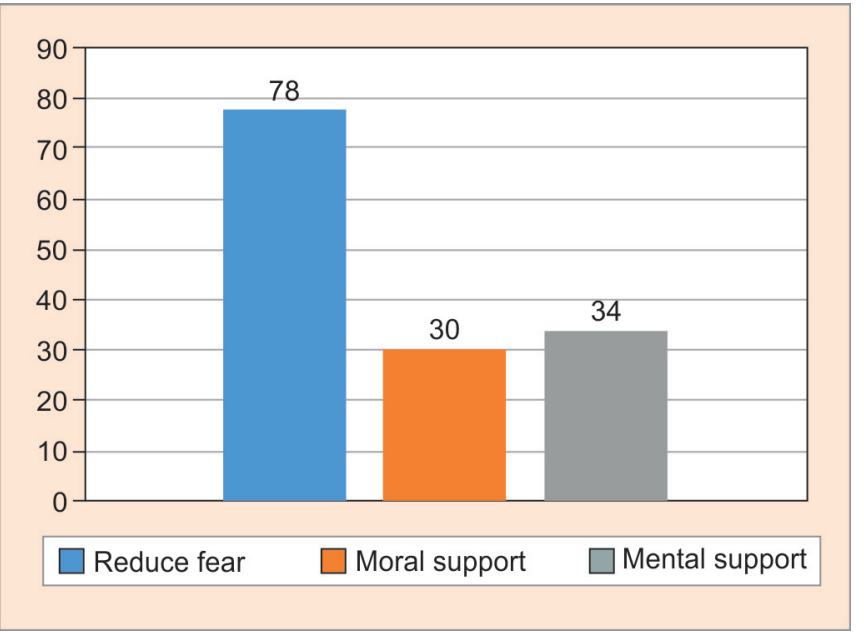

Fig. 2: Benefits of allowing family members with the patient

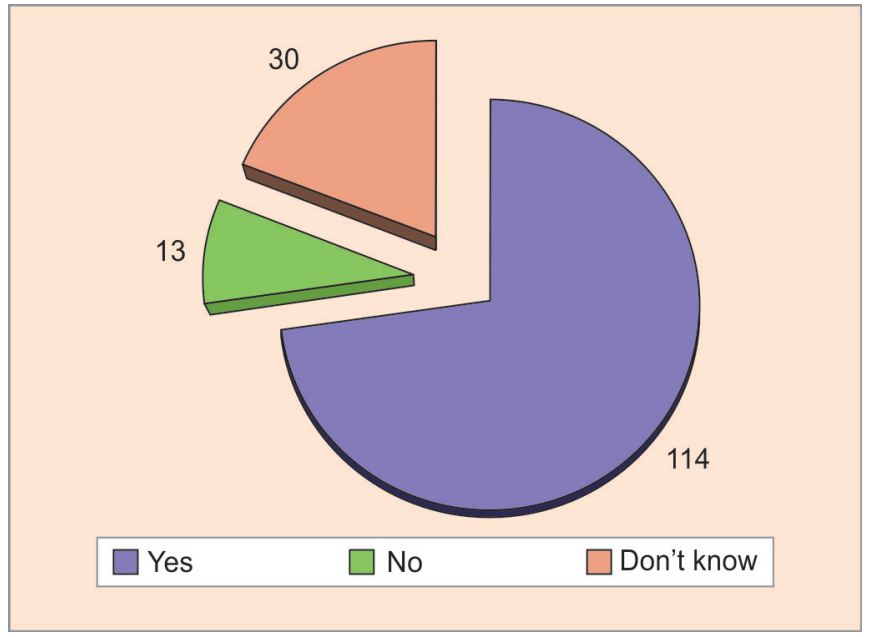

Fig. 4: Role of family members in $\mathrm{HAl}$

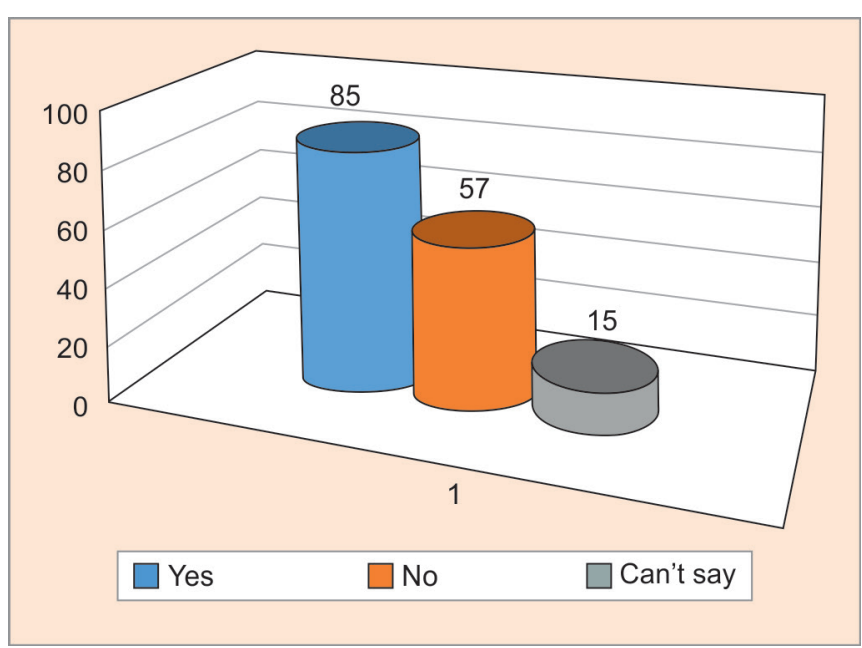

Fig. 6: Should provision for the patient's family members stay be considered during ICU planning? 


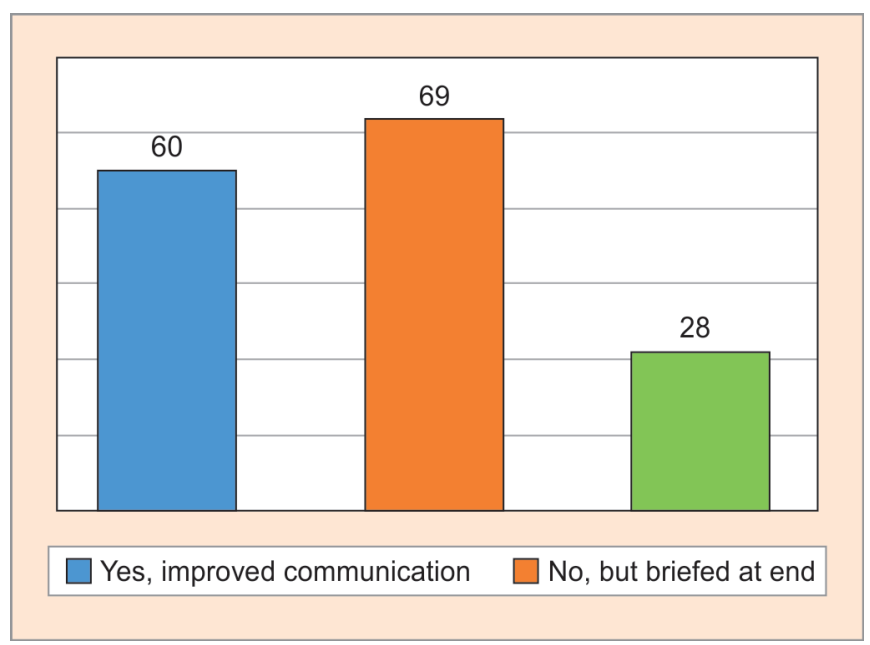

Fig. 7: Could relatives be part of clinical round?

\section{Role of Family in the Feeding}

In the present study, $89.2 \%$ of the respondents feel that the relatives are helpful in feeding of the patients. The finding are in contrast with the finding of a Belgian study wherein the nursing staff did not feel so. ${ }^{8}$

\section{Role of the Family Members in Patient Safety Incidences}

A total of $73.25 \%$ of the respondents opined that the presence of family members can help in the reduction of adverse patient safety incidences. It has been stated that the presence of family members improve communication and information-sharing between the healthcare worker and patients, which in turn help in prevention of adverse events. The study is sync with the Belgian study by Asiain et al., where hospital staff strongly disagreed with the possibility of an increase in errors with the presence of visitors. ${ }^{8}$

\section{Potential Negative Effects of the Relative Presence Role of Family Members in Hospital-acquired Infections}

Of the total respondents, 114 (72.61\%) perceived that the presence of family members increased the incidence of HAI, 30 (19.10\%) were not sure, and 13 (8.28\%) felt that they had no role in HAI.

\section{Privacy of the Patients}

Participants also expressed concerns related to privacy of the patients. Forty HCWs opined that patient privacy was often an issue, 68 respondents said it was an occasional problem, while 49 said it was rarely an issue. The privacy of the patient has been stated to be an important issue in the mind of staff nurses from Belgium. ${ }^{8}$

\section{Ground Reality of the Patient Stay During Night}

After excluding the multiple answers, it was found that, $54.30 \%$ respondents agreed that relatives were staying in the ward during night with the patient (although no provision for them had been made) and $32.45 \%$ respondents said that they stayed in corridors. Only $12.74 \%$ said they stayed in the waiting areas outside the hospital.

\section{Are the Provisions Made for the Family Members Sufficient?}

$64.33 \%$ (101) of the respondents felt that provisions made for the relatives were inadequate and requirements of family should be

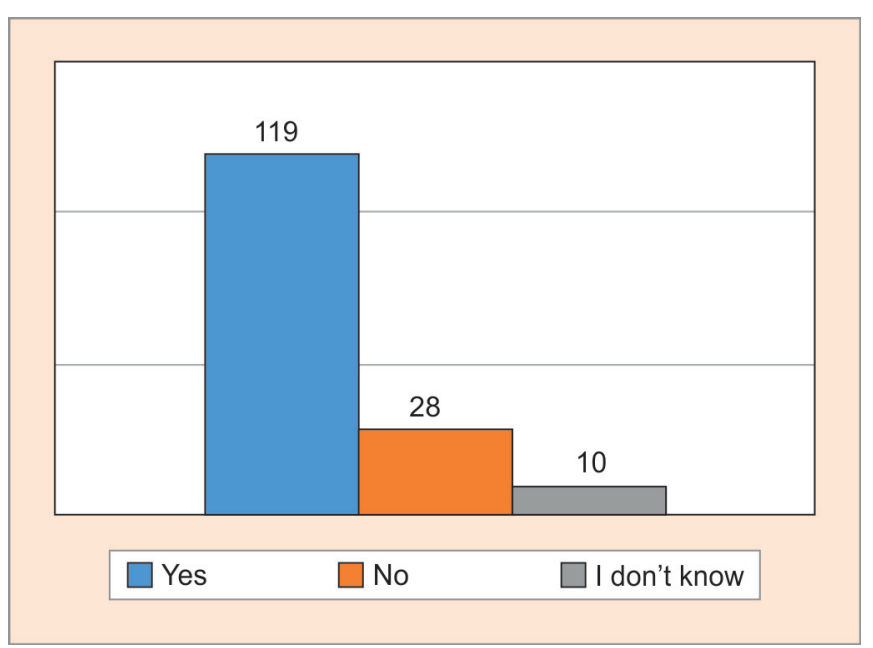

Fig. 8: Should family be provided with foldable furniture?

considered during the planning stages, whereas 36 (19.11\%) felt that the provisions were adequate. Rest had no firm opinion.

\section{Consideration for Family in Planning Premises of ICU Design}

$55.41 \%$ of the respondents favored the consideration of provisions for staying of family members during planning of ICU, whereas $36.31 \%$ were against the considerations and rest were not sure.

\section{Involvement of Family Members in Clinical Rounds}

In the present study, $43.95 \%$ respondents were against the involvement of family members during clinical rounds, whereas $33.22 \%$ opined that family members should be present during clinical rounds. The possible reasons may be low literacy of general patient (particularly medical literacy), misplaced belief about medical conditions, irrelevant questions, and unjustified expectations of the family.

\section{Provisions of Infrastructure for Stay of Family Members in the Patient Care Area}

119 HCWs (75.8\%) felt that family members should be provided with at least some form of foldable furniture for rest, whereas 28 (17.84\%) were against provision of furniture and $10(6.37 \%)$ had no opinion.

\section{Factors Responsible for Framing the Opinion}

What is there in the mind of HCW, which is responsible for such overwhelming support for allowing family in the ward? On applying Chi-square test on the HCWs opinion about allowing family in ward, it emerged that ease of handling patient, concern for sentinel events, educational qualification, privacy of patients and Apprehension about $\mathrm{HAl}$ were the factors with a $p$ value of less than 0.001 , which meant that these factors were the major variables in forming opinion about family involvement in patient care of admitted patients.

\section{Discussion}

Hospitals as a concept in its present form is 100 years old. It, being a social organization, has taken different sizes and the shapes which were affected by variation in the social structures, belief, and customs and value system of the respective geographical locations. ${ }^{10}$ While in European countries it is an accepted norm that patient will spend his/ her night in hospital alone, without any family members or friends 
in hospital. In Asian countries this is not the case. The restricted visitors' timing and other restrictions for the family members are now being challenged in western countries. Proponents of patients and family-centric care have favored more involvement of family in decision-making and participation in patient care.

It has been established that the presence of relatives may not be associated with increased incidences of septic infection even in ICU. ${ }^{4}$ On the contrary, it is related to reduction in the incidences of cardiovascular episodes and thyroid-stimulating hormone level, reduction in anxiety scores, and lower mortality.

Not many studies that looked into the role or task performed by family members to supplement the efforts of HCW were found.

An overwhelming majority of staff members approved the stay of the family members with patient and their attitude was not influenced by age, gender, numbers of years of services, area of posting, or work assigned.

In Indian settings, it is usually observed that family members assume a significant role in non-clinical care of the patient, including nutrition and hygiene, clothing and sponging, arranging supplies not available in hospital supply. They also provide the moral support to the patient and act as a channel of communication between the hospital staff and patient.

However, education was found to be inversely related to the approval of the stay of family members in hospital. It might be due to the direct relation of education with earning. It has also been reported that poor get less-dignified treatment, lesser choice of provisions, and poorer quality of amenities. ${ }^{11}$

The experience of the respondents that the patients with family member are easier to handle, while it is more difficult to handle unknown and unattended patients was one of the factors responsible for a favorable attitude toward relatives' stay in the ward.

The role that the family members played in a patient's nutrition was favored by respondents in the present study. The role of the family members need to be further studied, particularly in cases of patients with catabolic conditions requiring special/higher nutrition.

Respondents also felt that patient safety sentinel events are reduced by the presence of the family members.

Role of relatives in increasing $\mathrm{HAl}$ is very difficult to understand. Though $72.16 \%$ of the respondents feel that relatives contribute toward HAl, but they still favor their stay and it is significant.
The respondents who expressed their concerns about the provisions for the relatives were also in favor of patients being allowed in ward.

\section{Recommendation}

Hospitals should rethink about the role played by the relatives in the overall care of patients. The design of hospitals need to be modified so as to incorporate provisions to allow relatives' stay with patients. There is a need for more studies on the debates about the role of family members during the patient care at hospital and thereafter.

\section{References}

1. Ismail S, Mulley G. Visiting times. BMJ 2007 Dec 22;335(7633): 1316-1317. DOI: 10.1136/bmj.39420.392373.BE.

2. Fumagalli S, Di Bari M, et al. Reduced Cardiocirculatory Complications With Unrestrictive Visiting Policy in an Intensive Care Unit. Results from a Pilot, Randomized Trial. Circulation 2006;113:946-952.

3. Kleinpell RM. Visiting hours in the intensive care unit: More evidence that open visitation is beneficial. Crit Care Med 2008 Jan;36(1): 334-335. DOI: 10.1097/01.CCM.0000295266.17378.BD.

4. Marco L, Bermejillo I, et al. Intensive care nurses' beliefs and attitudes towards the effect of open visiting on patients, family and nurses. Nurs Crit Care 2006 January 3;11(1):33-41. DOI: 10.1111/j.13621017.2006.00148.x.

5. Cadenhead CD, Anderson DC. Critical Care Unit Design, The Winners and Future Trends: An Investigative Study. World Health Design Journal 2009;2(3):72-77.

6. Davis R, Savvopoulou M, et al. Predictors of healthcare professionals' attitudes towards family involvement in safety-relevant behaviours: a cross-sectional factorial survey study. BMJ Open 2014;4:e005549. DOI: 10.1136/ bmj open-2014-005549.

7. Sims JM, Miracle VA. A look at critical care visitation: Thecase for flexible visitation. Dimens Crit Care Nurs 2006 july;25(4): 175-180.

8. Berti $D$, Ferdinande $P$, et al. Belief and attitudes of intensive care nurses toward visits and open visitng policy. Intensive Care Med 2007;33:1060-1065. DOI: 10.1007/s00134-007-0599-x.

9. http://www.npsa.nhs.uk/nrls/reporting/what-is-a-patient-safetyincident/.

10. Smith L, Harrison MB. The impact of hospital visiting hour polices on paediatric and adult patients and families. JBI Library Syst Rev 2006 Dec 03;4(10):1-14.

11. Musgrove P, Creese A, et al. The World health report 2000: health systems: improving performance. 1211 Geneva 27, Switzerland: World Health Organization; 2000. p. 206. 